\title{
Ground-based remote sensing profiling and numerical weather prediction model to manage nuclear power plants meteorological surveillance in Switzerland
}

\author{
B. Calpini ${ }^{1}$, D. Ruffieux ${ }^{1}$, J.-M. Bettems ${ }^{1}$, C. Hug ${ }^{1}$, P. Huguenin ${ }^{1}$, H.-P. Isaak ${ }^{2}$, P. Kaufmann ${ }^{1}$, O. Maier ${ }^{1}$, and \\ P. Steiner ${ }^{1}$ \\ ${ }^{1}$ Federal Office of Meteorology and Climatology MeteoSwiss, Switzerland \\ ${ }^{2}$ Swiss Federal Nuclear Safety Inspectorat ENSI, Switzerland
}

Received: 1 October 2010 - Published in Atmos. Meas. Tech. Discuss.: 28 January 2011

Revised: 28 July 2011 - Accepted: 29 July 2011 - Published: 23 August 2011

\begin{abstract}
The meteorological surveillance of the four nuclear power plants in Switzerland is of first importance in a densely populated area such as the Swiss Plateau. The project "Centrales Nucléaires et Météorologie" CN-MET aimed at providing a new security tool based on one hand on the development of a high resolution numerical weather prediction (NWP) model. The latter is providing essential nowcasting information in case of a radioactive release from a nuclear power plant in Switzerland. On the other hand, the model input over the Swiss Plateau is generated by a dedicated network of surface and upper air observations including remote sensing instruments (wind profilers and temperature/humidity passive microwave radiometers). This network is built upon three main sites ideally located for measuring the inflow/outflow and central conditions of the main wind field in the planetary boundary layer over the Swiss Plateau, as well as a number of surface automatic weather stations (AWS). The network data are assimilated in real-time into the fine grid NWP model using a rapid update cycle of eight runs per day (one forecast every three hours). This high resolution NWP model has replaced the former security tool based on in situ observations (in particular one meteorological mast at each of the power plants) and a local dispersion model. It is used to forecast the dynamics of the atmosphere in the planetary boundary layer (typically the first $4 \mathrm{~km}$ above ground layer) and over a time scale of $24 \mathrm{~h}$. This tool provides at any time (e.g. starting at the initial time of a nuclear power plant release) the best picture of the 24-h evolution of the air mass over the Swiss Plateau and furthermore generates the input data (in the form of simulated values substituting in situ ob-
\end{abstract}

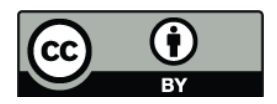

Correspondence to: B. Calpini (bertrand.calpini@meteoswiss.ch) servations) required for the local dispersion model used at each of the nuclear power plants locations. This paper is presenting the concept and two validation studies as well as the results of an emergency response exercise performed in winter 2009.

\section{The former safety tool}

The main environmental concerns affecting the acceptance of nuclear power plants (NPP) by the public are the emission of radioactive materials, the potential for nuclear accidents, and the generation of radioactive waste. NPP meteorological surveillance is a very important task in the frame of risk assessment regarding the two first issues. The 1986 Chernobyl NPP accident was an event with dramatic consequences at the local, regional, and international scales (Pudykiewicz, 1988). In Switzerland, the former safety tool was based on meteorological towers and in situ observations of wind and temperature measurements at different heights up to $120 \mathrm{~m}$ above ground level (a.g.l.) installed at the NPP sites thus measuring the meteorological conditions within the surface layer. These data were used as input data either directly into a Gaussian-type model or, combined with a climatological wind pattern selected with additional wind data from neighbouring stations, into a Lagrangian model to forecast the shape of potential radioactive plumes and their dispersion at the local scale (Schorling, 2000). This former safety tool was developed over many years at each of the NPPs sites, and a number of field experiments were conducted using surface automatic weather stations (AWS) and remote sensing instruments, in particular wind measurements performed by Doppler Sodar and tethered balloon

Published by Copernicus Publications on behalf of the European Geosciences Union. 
measurements (Bellinger, 2005). The resulting data set was used for defining typical "wind classes" (Kaufmann, 1996) at each of the NPPs thus giving an empirical climatology of the sites accordingly. In situ observations from the AWS, meteorological masts, and model predictions were the input conditions for the retrieval of the appropriate wind class used for the Lagrangian model which was then providing adequate forecasts at low altitude (below $500 \mathrm{~m}$ a.g.l.). The limitation of this system was a very rough differentiation in the vertical dimension within the planetary boundary layer as well as a relatively strong discretisation of the wind information through the wind classes. Vertical wind shear could only coarsely be captured and only if sufficiently represented in the selected wind class and was totally neglected for the Gaussian model.

\section{The new safety tool}

\subsection{Model development}

MeteoSwiss operates its own short-range numerical weather prediction (NWP) system. The core of this system is the fully compressible non-hydrostatic model developed by COSMO (the Consortium for Small-Scale Modelling, currently composed of the national weather services of Germany, Switzerland, Italy, Greece, Poland, Romania and Russia - see http:// www.cosmo-model.org/. The COSMO model includes a full set of physical parameterizations suited for weather prediction applications (Steppeler et al., 2003). The Newtonian relaxation technique known as nudging (Schraff, 1997) is used to produce the initial conditions for each forecast; although simple, this method is an efficient way to nudge the state of the model towards the real state of the atmosphere. Being the primary tool for official duty at the COSMO Weather Services, special focus is put on operational stability as well as efficiency and portability, suitability for moist and particular processes of special interest to COSMO members.

During the CN-MET project, the MeteoSwiss NWP system has been substantially extended in order, among others, to fulfill the new requirements of the project which were to obtain the best wind field forecasts over the Swiss Plateau from the ground to the top of the planetary boundary layer with the highest spatial resolution (e.g. the best topography for the Swiss Plateau and the surrounding Jura mountains and the Alps) over a time scale of $24 \mathrm{~h}$. A new high resolution component with a focus on the Alpine region has been developed, the so-called COSMO-2, and a special effort has been invested to feed the nudging process with ground-based remote sensing devices such as wind profilers.

The resulting NWP system of MeteoSwiss is composed by two nested COSMO models, driven by IFS, the operational global model operated by the European Centre for Medium-Range Forecasts (ECMWF). The COSMO-7 component is computed on the western part of Europe, with a mesh size of $6.6 \mathrm{~km}$, and is used to compute 3 day forecasts, starting daily at 00:00 UTC, 06:00 UTC, and 12:00 UTC. The high resolution component COSMO-2 is computed on the Alpine region, with a mesh size of $2.2 \mathrm{~km}$, a vertical resolution that ranges from about $20 \mathrm{~m}$ (first layer of the model above ground) up to about $1000 \mathrm{~m}$ (top layer at an altitude of $20 \mathrm{~km}$ ) with 60 layers, and is used to compute one day forecast eight times daily (the every three hours rapid update cycle). Unlike COSMO-7, the COSMO-2 model is convection permitting because the deep convection is not parameterized but explicitly resolved. COSMO-2 uses also a latent heat nudging scheme (Rossa, 2009) to correct the convection in the analysis step by using precipitation derived from radar composite.

The COSMO-7 domain extends from $35.16^{\circ} \mathrm{N}-9.80^{\circ} \mathrm{E}$ (lower left) to $56.84^{\circ} \mathrm{N} 23.02^{\circ} \mathrm{E}$ (upper right) and is covered by a grid of $393 \times 338$ points. The COSMO- 2 domain extends from $42.72^{\circ} \mathrm{N} 2.25^{\circ} \mathrm{E}$ (lower left) to $49.76^{\circ} \mathrm{N}$ $17.25^{\circ} \mathrm{E}$ (upper right) and is covered by a grid of $520 \times 350$ points. The West and South borders of the COSMO-7 domain have been placed over sea in order to reduce negative interferences generated in the transition zone between the topographies of the driving model (IFS) and COSMO-7. In an analogous way, the boundaries of the COSMO-2 domain have been chosen to run in plane terrain in order to avoid such kind of interferences between the topographies of COSMO7 and COSMO-2. The grids are defined in such a way that each COSMO-7 grid point coincides with one point of the COSMO-2 grid inside the COSMO-2 domain.

The post-processing package requested by the Swiss Federal Safety Inspectorate is defined on a domain covering an area including all grid points within $50 \mathrm{~km}$ from the nuclear power plants, or an equivalent of $85 \times 85$ grid points from ground level up to $2000 \mathrm{~m}$ a.g.l. On this subset, COSMO-2 output is collected every $10 \mathrm{~min}$, instead of the usual $60 \mathrm{~min}$ on the full domain. In case of emergency, an "on demand" COSMO-2 task is started with a $6 \mathrm{~h}$ forecast performed every single hour; this emergency mode can last up to one day. Such "on demand" or crisis mode requires a fast response of the system. A maximum time to solution of $20 \mathrm{~min}$ for the COSMO-2 production suite is allowed between the triggering of the job on the supercomputer and the end of the time critical part of the post-processing.

\subsection{Network development}

A combination of surface measurements and ground-based remote sensing techniques (Calpini, 2008, Ruffieux et al., 2009) constitutes the CN-MET observation network (see Fig. 1). The three low-tropospheric $(1290 \mathrm{MHz})$ wind profilers combined with three passive microwave radiometers provide a continuous observation of the planetary boundary layer dynamics over the Swiss Plateau. Currently only the wind profiler data with a vertical resolution of $57 \mathrm{~m}$ from $106 \mathrm{~m}$ a.g.l. up to $3203 \mathrm{~m}$ a.g.l. (high resolution mode) 
and resp. $143 \mathrm{~m}$ vertical resolution from $300 \mathrm{~m}$ a.g.l. to $8,000 \mathrm{~m}$ a.g.l. (low resolution mode) and a effective time resolution of one vertical profile every 30 min (profiles are generated on a 10 min sampling time using gliding average methods over $30 \mathrm{~min}$ ) are real time assimilated into the $\mathrm{CN}$ MET tool. The passive microwave temperature and humidity vertical profiles are still in a validation phase and therefore not yet assimilated into COSMO-2.

These sites are located at three strategic locations within the region: two at in- and out-flow boundaries corresponding to the predominant wind conditions over the Swiss Plateau, and one in the centre of the domain.

The operational radio-sounding station of Payerne, located at the south-western part of the domain, provides twice a day the state of the atmosphere with pressure, temperature, humidity and wind profiles.

At each of the NPPs, a new AWS is equipped with standard meteorological measurements plus a sonic anemometer for $10 \mathrm{~m}$ turbulence measurements and a radioactivity sensor. These AWSs provide real time local observations of the weather conditions in the direct surrounding of each of the four NPPs.

In the new safety tool, the vertical profile of wind, temperature, and turbulence values at each of the four NPPs are obtained using directly the simulated values from COSMO-2, thus the former high meteorological masts, bearing high costs for maintenance, have been dismantled. This has the consequence that the input data for the Gaussian and Lagrangian models around each NPP are no more obtained from the in situ observations of the respective meteorological mast but directly from the numerical output of the fine grid numerical weather prediction model COSMO-2.

Finally, four television towers in the surrounding of the nuclear sites are equipped with wind and temperature sensors, and provide an additional dataset for validation of the model results.

Similar studies where boundary layers measurements are used for data assimilation in numerical weather prediction models can be found for example in Yates, (2009); Furumoto, (2007); St-James, (2005); Smith, (1993) and Benjamin, (2004). There is so far and to our knowledge no similar example where in situ observations have been cancelled and replaced by fine grid NWP output to be used as initial conditions for dispersion models.

The CN-MET network is connected to SwissMetNet (SMN), the new Swiss meteorological network of MeteoSwiss. SMN is a central platform for collection and distribution of the meteorological and technical (housekeeping) parameters measured at each of the ground based surface and upper-air stations. This central platform allows having on the same network all the necessary on-line and real time technical parameters necessary for a continuous monitoring and maintenance of the network.

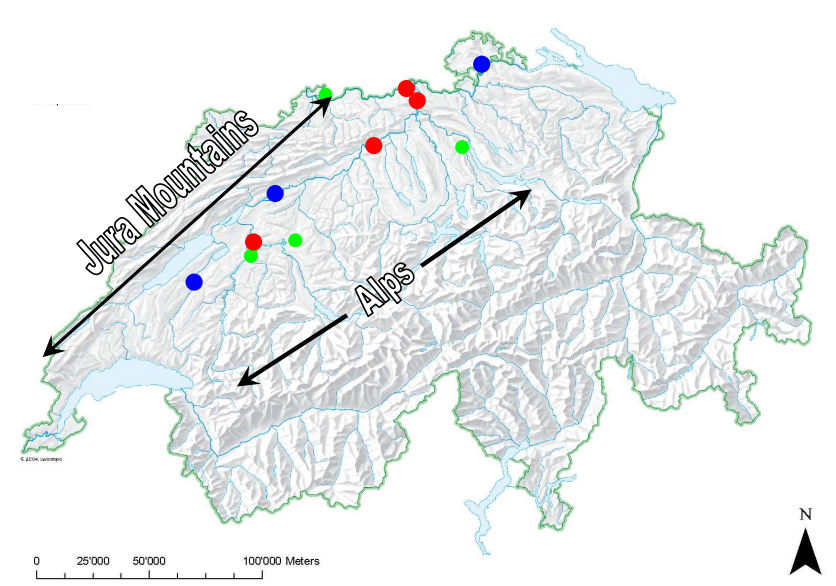

Fig. 1. CN-MET measurement network. Red dots correspond to the 4 nuclear power plants locations with surface in-situ measurements (from SW to NE: Mueleberg, Goesgen, Beznau, and Leibstadt), blue dots to the three upper-air ground-based remote sensing sites with low-tropospheric wind profilers and microwave radiometers (from SW to NE: Payerne, Grenchen, and Schaffhausen), and green dots to in-situ measurements located on television towers.

\section{Validation studies}

\subsection{Campaigns}

Two validation campaigns were organized in order to check the ability of COSMO-2 to forecast wind fields over the Swiss Plateau in this complex topography. An independent (not assimilated) mobile wind profiler was installed in the domain at two different places and for two different seasons of the year. This mobile wind profiler has lower performances than those located in the three CN-MET sites namely with a vertical resolution of $72 \mathrm{~m}$ from $219 \mathrm{~m}$ a.g.l. up to $1131 \mathrm{~m}$ a.g.l. (high resolution mode) resp. $205 \mathrm{~m}$ vertical resolution from $454 \mathrm{~m}$ a.g.l. to $4452 \mathrm{~m}$ a.g.l. (low resolution mode) and a time resolution of $30 \mathrm{~min}$ (Hug et al., 2009). In Fig. 2 the mobile wind profiler data availability is given for both modes versus the altitude range. For each of the two validation studies the total measured data sample (wind speed and wind direction vertical profiles) was above 10000 thus giving a robust estimate when comparing wind measurements in the planetary boundary layer against numerical results from COSMO-2. Since these comparisons are limited to the maximum achievable range obtained by the mobile wind profiler data, the statistical analysis between measured and model results presented here below is restricted to the first 20 layers of COSMO-2.

The first validation campaign lasted from August to October 2008 (3 month duration). The independent wind profiler was located in Kleindoettingen close to both the Beznau and Leibstadt NPPs (Fig. 1). This site is located in the Aare Valley (south-north oriented) cutting through the Jura Mountains. The Rhine valley (east-west oriented) is separated from 

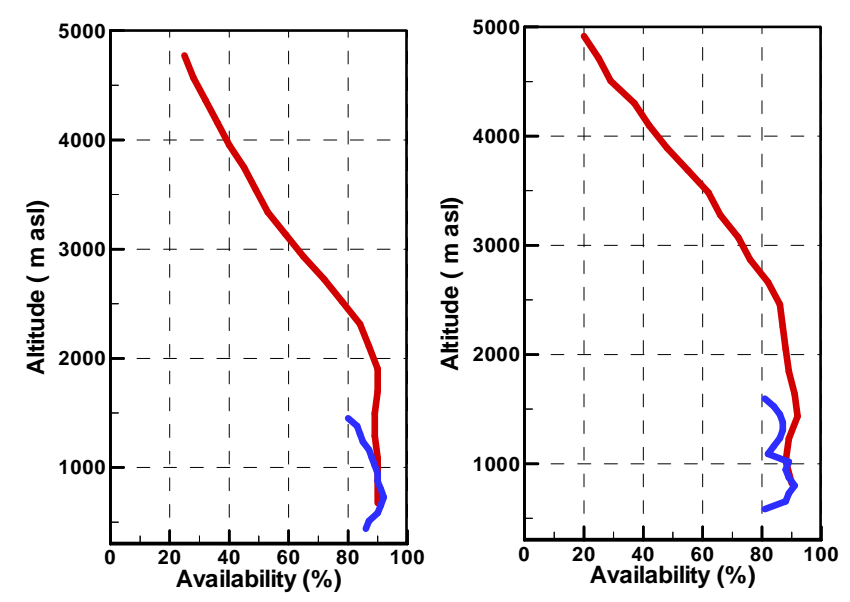

Fig. 2. Data availability versus altitude range of the independent wind profiler mobile unit during the two validation observation periods in Kleindoettingen 2008 (left panel) and Muehleberg 2009 (right panel) for the high resolution mode (blue line) and low resolution mode (red line). The total amount of data sample for each campaign was over 10000 .

Kleindoettingen by a low ridge. This overall hilly orography is well representative of a low altitude site on the Swiss Plateau.

The second validation campaign lasted from mid of March until the end of June 2009 (3.5 month duration) with the same mobile wind profiler located in Wileroltigen in the Saane Valley near the Muehleberg NPP (Fig. 1). In this case the local orography was more complex than the one of the first campaign. The main orientation of the Saane valley is northsouth while the Muehleberg NPP lies in the narrow Aare valley with an east-west orientation. This offered an opportunity for a second analysis of the performance of COSMO-2 during the spring season and typical of air flow conditions with strong orographical effects.

The two field campaigns allowed for validation studies between independent wind profiler observations and wind profiles forecasted by COSMO-2 at two significantly different places along the Swiss Plateau and for two different seasons of the year. While both campaigns showed overall similar results, only statistical analysis of the first one is described below as an example.

\subsection{Results of the validation campaigns}

Figure 3 gives the direct comparison between model and measured results (wind speed and wind direction bias and standard deviation) as obtained during the Kleindoettingen 2008 validation campaign. The main conclusions of these two validation studies in Kleindoettingen 2008 and Muehleberg 2009 can be summarized as follows.

The wind speeds forecasted by COSMO- 2 were in remarkably good agreement with the measurements. The bias be-

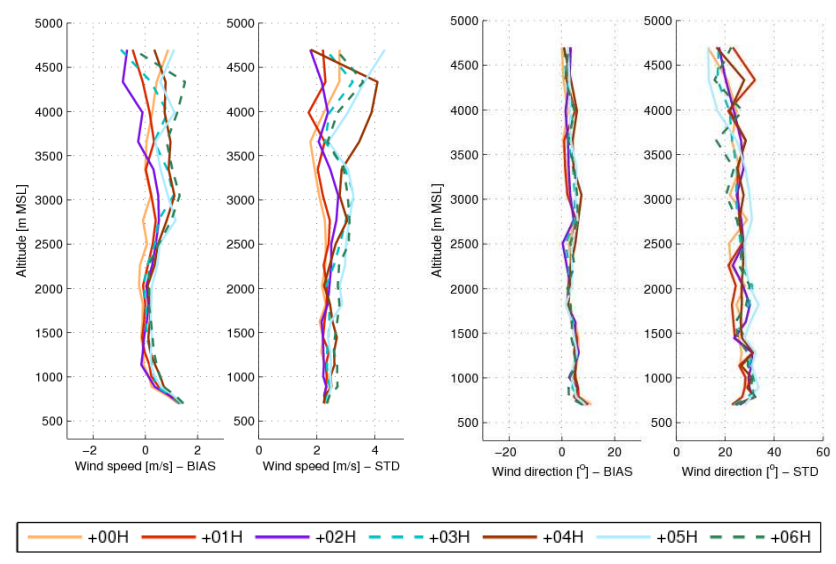

Fig. 3. Vertical profiles of wind speed bias (COSMO2-WP) and standard deviation for wind speed values between 1 and $10 \mathrm{~ms}^{-1}$ (left panels) and wind direction bias and standard deviation for wind speed above $3 \mathrm{~ms}^{-1}$ (right panels), for the first 6 forecast hours, Kleindoettingen, 1 August 2008-31 October 2008.

tween model and measured results was typically lower than $\pm 1 \mathrm{~ms}^{-1}$ (STD lower than $4 \mathrm{~ms}^{-1}$ ) with slightly decreasing performances close to the ground (typically in the first $300 \mathrm{~m}$ a.g.l.). This analysis was also performed for the first $6 \mathrm{~h}$ of the forecast separately with very similar results with respect to the one hour head time. This result confirms the ability of the new model to capture the wind field over the Swiss Plateau.

The wind directions forecasted by COSMO-2 were also in good agreement with the measurements. The bias between model and measurements was typically lower than \pm 10 degrees (STD lower than 40 degrees) and here again with slightly decreasing performances close to the ground. In terms of directions, a weaker performance was observed for lower wind speed conditions due to the higher variability in wind directions. On the other hand this performance became better for wind speed higher than $3 \mathrm{~ms}^{-1}$ and for higher altitude range above ground. The higher altitudes were studied using the wind profiler in its low resolution mode with good signal to noise measurements up to a typical altitude range of $4500 \mathrm{~m}$ a.g.l.

These two validation studies also underlined some limitations of COSMO-2 compared to the wind profiler observations. In the case of strong and rapid weather changes (front passages, foehn events, ...) involving short-time changes in wind direction and speed, the model was not always able to accurately capture the time and spatial dynamics of these events. Temporal shifts between model and measurement were mainly responsible for the larger biases in the model values. Such weather situations typically occurred less than $20 \%$ of the time; in these cases, the model needs to be improved, further development being currently undertaken including the investigation of a model with a $1 \mathrm{~km}$ horizontal mesh. 


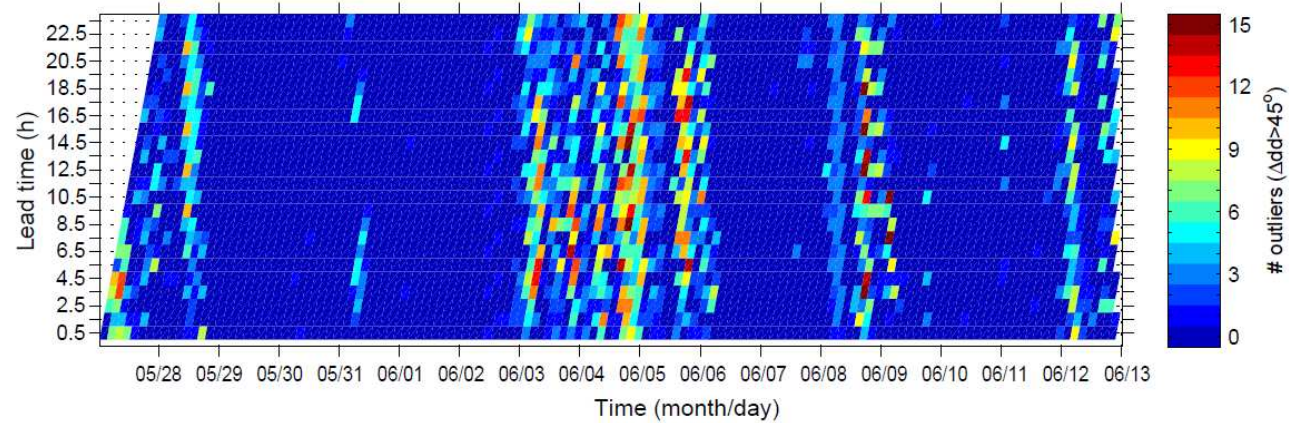

Fig. 4. Wind direction outliers in the time series from 28 May to 13 June 2009, during the Muehleberg 2009 validation campaign: outliers are defined as (modelled-measured) wind direction values exceeding 45 degrees at all COSMO-2 layers ranging from the ground layer up to layer \#15 (colour scale ranges from blue equal "no outlier" to dark red equal to "all 15 layers" have outliers values). Each data point is expressed for any lead time in hours ranging from the COSMO-2 analysis time to a one day forecast, by step of $0.5 \mathrm{~h}$. The time series from 3-6 June (see the synoptic weather map in Fig. 5) is an example of poorly predicted weather conditions. These statistics are performed using only wind speed conditions higher than $2 \mathrm{~ms}^{-1}$.

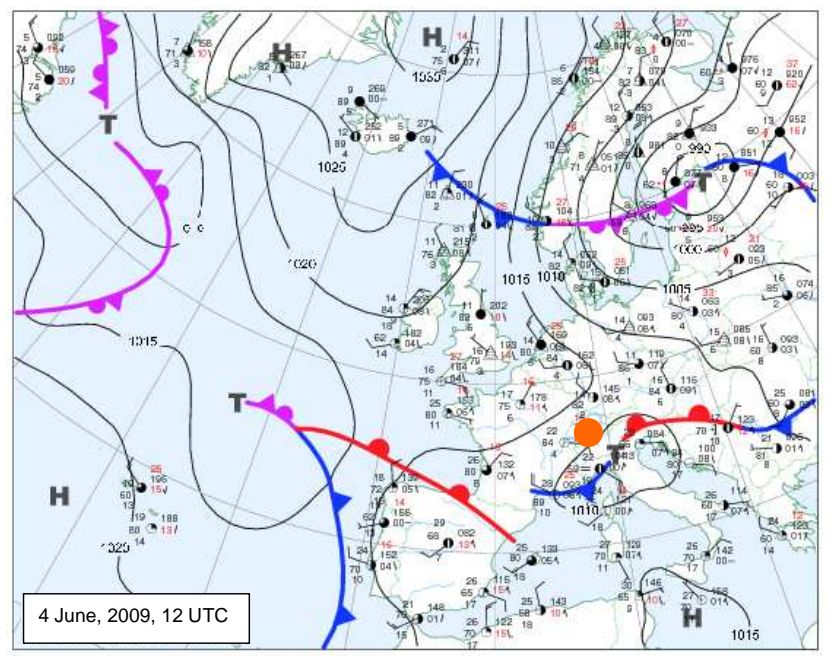

Fig. 5. Synoptic situation above Europe (surface), 4 June 2009, at 12:00 UTC. Area of interest is shown with an orange circle.

One example of the effect of rapid weather changes on the performance of COSMO-2 is given in Fig. 4, with the weather synoptic map of midday 4 June 2009 in Fig. 5. The beginning of June 2009 was characterized by a complex weather situation evolving over Switzerland from a weak northeasterly flow (2 June 2009), to a northwesterly flow (3 June 2009), with the passage of a cold front (4 June 2009), before to switch to a westerly perturbed flow (5 June 2009).

In Fig. 4 each data point represents on the horizontal axis the time step of the every $3 \mathrm{~h}$ ( 8 times a day) COSMO-2 runs, on the vertical axis the lead time (time between the COSMO-2 run and the forecast e.g. from the analysis to the next $24 \mathrm{~h}$ forecast time), and the color code gives the number of outliers for the first 15 layers of the model from the ground to $3500 \mathrm{~m}$ a.s.l. between the measured and the numer- ical value, integrated over the 15 layers. Blue color indicates no direction outlier of more than 45 degrees, while dark red means that, at all altitude ranges, the differences between model and measured wind directions are all larger than 45 degrees. With this statistical analysis the period of time inbetween 3-6 June 2009 shows a clear discrepancy between measured and modeled values. This analysis was performed for the two entire periods of observation in 2008 and 2009, and for both wind speeds and directions, and showed very consistent results thus allowing for a first estimate of ca. $20 \%$ of the time when discrepancy between model and measured weather conditions over the Swiss Plateau is still large. Note that the discrepancy appeared to be essentially independent of the lead time. This reinforces the argument of rapidly changing weather conditions (front passage) for which the model may be out of phase in time versus the current measured weather condition while the absolute wind speed conditions remain quite accurately forecasted.

Another weakness was found for lower altitude validation, typically for values in the range from the ground level up to about $300 \mathrm{~m}$ a.g.l. This might partially be caused by an intermittent ground clutter contamination of the wind profiler's first gates (May, 1998). On the model side, a new numerical scheme was introduced in September 2009 to include the impact of sub-scale orographical features in the model. This scheme improved the quality of the forecast in the boundary layer. In addition, the vertical level distribution of COSMO-2 will be improved in the near future. A finer vertical spacing of the grid levels close to the ground will provide more accurate values within the boundary layer.

An essential impact on the quality of the new COSMO-2 operational mode was found in the increased repetition rate of the model runs: the model forecasts are calculated every three hours while the COSMO-7 is run three times per day. With this 3-hourly data assimilation cycle, the newest and most accurate picture of the atmosphere from both 


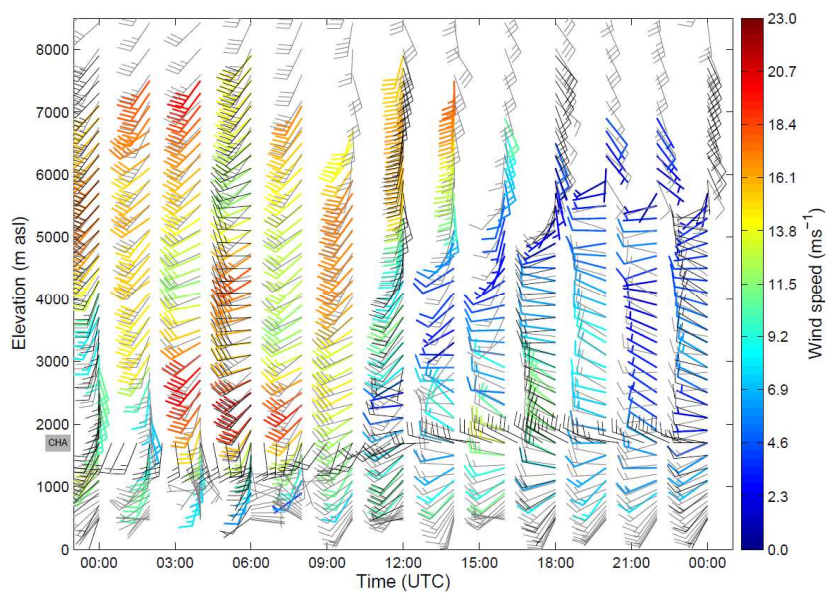

Fig. 6. Typical example of a one-day wind profile time series at Payerne (5 February, 2010). Coloured barbs: wind profiler measurements; grey barbs: COSMO-2 profiles (analyses every $3 \mathrm{~h}$ followed by $3 \mathrm{~h}$ forecasts); CHA dark grey barbs: 10-m a.g.l. in situ wind measurements on top of the nearby Jura mountain at Chasseral $1600 \mathrm{~m}$ a.s.l. (for clarity the data display is given only every $2 \mathrm{~h}$; the effective sampling time is $10 \mathrm{~min}$ ).

observations and numerical model analysis is obtained. This positive impact of the rapid update cycle was also demonstrated and quantified during the MAP D-Phase campaign (Weusthoff, 2010).

Finally the two validation studies underlined the need for a quality estimate for the model output. Since there remain weather conditions for which the model is not able to fully capture the weather conditions, this security tool designed to support decision making in case of nuclear accidents needs to be delivered with a "quality index", thus providing a quasi real-time quality index of the forecast. This index however is still to be developed.

Figure 6 gives an integrated view of several on-line realtime information from the CN-MET network and model outputs: the wind profile time series at Payerne are given up to a height of $8.5 \mathrm{~km}$ a.s.l. as measured by the wind profiler with wind directions expressed by the wind barbs and wind speeds by the color coded scale. The grey color barbs are the COSMO-2 simulation results obtained from the 3hourly forecasts. The automatic weather station from Chasseral "CHA" at 1600 ma.s.l. is an AWS located on the Jura ridge $25 \mathrm{~km}$ north of Payerne. This wind profile display is updated every $10 \mathrm{~min}$ and allows for a real-time online check of the availability and agreement of the different information sources (in Fig. 6 the profiles are displayed every $90 \mathrm{~min}$ for clarity). It is used by the technicians in charge of the operation and maintenance of the network thus ensuring a better control of the whole CN-MET tool both for the measurements as well as the model outputs.

Instead of having only local information around the nuclear power plants, the new CN-MET tool offers the four

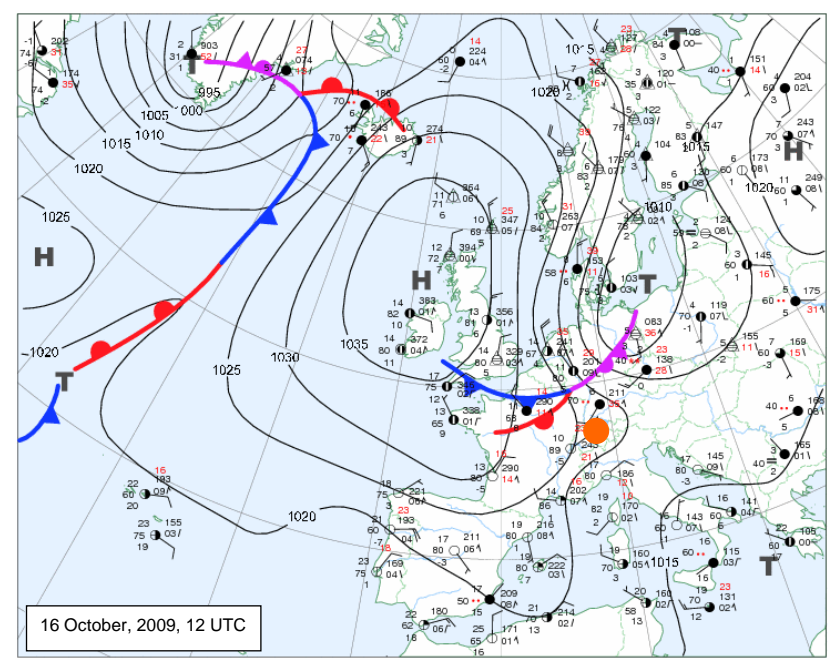

Fig. 7. Synoptic situation above Europe (surface), 16 October 2009 at 12:00 UTC. Area of interest is shown with an orange circle.

dimensional picture of the state of the atmosphere over the entire domain and nearly continuous in time, so in effect the complete four dimensional meteorology. Only a very small subset of data is used for the input conditions of the dispersion models. This can be summarized as going from "single in situ observations" tool to the real-time "four dimensional picture" of the atmosphere.

Since the operational start of CN-MET in late 2009, a live test of the performance of this new tool has been done on 16 October 2009 without any prior warning. The Nuclear Safety Inspectorate simulated an alarm and defined a fictitious leak from the NPP Muehleberg. The next section highlights the main results obtained during this event by the new CN-MET tool.

\section{Case study}

The 16 October 2009 case study was based on a virtual release of $2.7 \times 10^{12} \mathrm{Bqs}^{-1}$ at an elevation of $125 \mathrm{~m}$ a.g.l. from the NPP Muehleberg. The leak was initiated at 11 a.m. local time (09:00 UTC) and the exercise lasted until 7 p.m. in the afternoon, corresponding to a period of $8 \mathrm{~h}$. The synoptic weather situation over Switzerland (Fig. 7) was quite complex with the passage of a front characterized by a main northerly flow blowing in altitude while the winds were variable and relatively weak close to the surface. Figure 8 shows the wind profiles obtained in the center of the CN-MET domain in Grenchen by the time of this exercise. Note around midday the rapid change in wind direction as measured from the ground up to about $1500 \mathrm{~m}$ a.g.l.: in this altitude range the air flow on the Swiss Plateau is channeled by the Jura mountains and the Alps. 


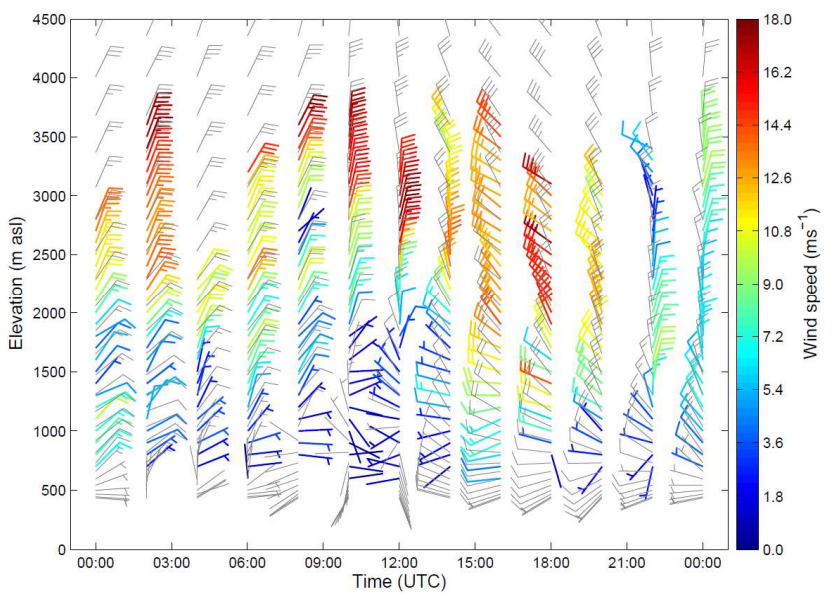

Fig. 8. The 16 October 2009 wind profile case study as measured (colour barbs) and modeled (grey barbs) in Grenchen in the centre of the CN MET domain. The altitude range is given for the high resolution wind profiler mode and the data display is given only every $2 \mathrm{~h}$.

The Atmospheric Dispersion Particle-In-Cell dispersion model ADPIC (Desiato 1991), based on COSMO-2 with assimilating, among others, the profiles measured by the three wind profilers, was able to forecast the complicated trajectory of the plume above Western Switzerland (Fig. 9).

The result was validated using an independent source of information. On the one hand, the dispersion output was obtained from the dispersion model run performed by the $\mathrm{Nu}-$ clear Safety Inspectorate using the CN-MET tool for the selection of the different wind classes as defined in Sect. 1. This is the result presented in the top row of Fig. 9. On the other hand, the simulation for the event was redone later using solely measurements for the determination of the wind classes, yielding a measurement based diagnosis of the case (bottom row of Fig. 9).

During the first $2 \mathrm{~h}$ after the radioactive release from Muehleberg, the simulated surface winds were blowing towards the southwest over the Swiss Plateau with an initial wind speed of up to a maximum of $5 \mathrm{~ms}^{-1}$. The forecast somewhat underestimates the wind speed and shows a less extended plume at 10:00 UTC. The fact that COSMO-2 is not able to reproduce the strong channeling at the NPP site however does not influence the direction of the spreading plume, because this channeling is restricted to a shallow layer just above the valley floor whereas the plume is transported by the faster and more voluminous winds above, as represented by the bold black arrow in Fig. 9. At approximately 12:00 UTC (three hours after the start of the release), the simulated wind turned into the northeasterly direction and the radioactive plume was transported backward (not shown). Later in the afternoon (see Fig. 9 at 14:30 UTC), the surface wind became stronger and was easterly oriented. The plume turned back accordingly, however parts of it were lost because it had travelled beyond the of the model boundary. Due to the lower wind speeds, this was less the case in the forecast, and the resulting plume $5.5 \mathrm{~h}$ after the release at 14:30 UTC contains higher concentrations. After the wind shift, the wind speed was still underestimated in the forecast, so that the cloud has already propagated further to the southwest in the diagnostic run.

This exercise underlined the new performance achieved by the CN-MET tool. The radioactive release was moving into one direction for the first $2-3 \mathrm{~h}$ after the release and then backward for the rest of the time period under investigation. These wind trajectories were adequately simulated thanks to the combination of the model with the necessary remote sensing observation (input conditions) over the Swiss Plateau.

In a later stage of the CN-MET system, implemented in 2010, the Swiss Nuclear Safety Inspectorate ADPIC Lagrangian model is directly embedded into the COSMO-2 Eulerian model without resorting to wind classes as intermediary information. Unfortunately, this improved system is not capable of simulating the past event of 2009 using the dispersion model directly embedded into COSMO-2. In this later version of the CN-MET system, no predefined wind classes are necessary any more.

\section{Summary}

The CN-MET tool is a combination of a dedicated measurement network including three ground-based remote sensing stations (equipped with a low-tropospheric wind profiler and a microwave radiometer) and the fine-scale NWP model COSMO-2. Twenty-four-hour forecasts are operationally produced every three hours in order to guarantee the meteorological surveillance of the Swiss territory for the unlikely case of a nuclear power plant accident.

Assimilation of upper-air winds measured within and above the planetary boundary layer has been introduced to improve the quality of the forecasts, especially at the regional and local spatial scales. Validation campaigns confirmed the overall good performances of COSMO-2 after assimilation of wind profiler data, even for complex weather situations. Wind biases between model outputs and an independent wind profiler were within \pm 10 degrees (STD lower than 40 degrees) and within $\pm 1 \mathrm{~ms}^{-1}$ (STD lower than $4 \mathrm{~ms}^{-1}$ ) for direction and speed respectively. These averaged performances have been obtained from two separate field campaigns. Meanwhile improvements must still be undertaken especially to better forecast wind fields very close to the ground or in the case of rapid weather changes.

Future work includes the model assimilation of temperature and humidity measured with microwave radiometers as well as the move to a finer spatial scale (COSMO-1) to improve the forecasts in such a complex topography. 

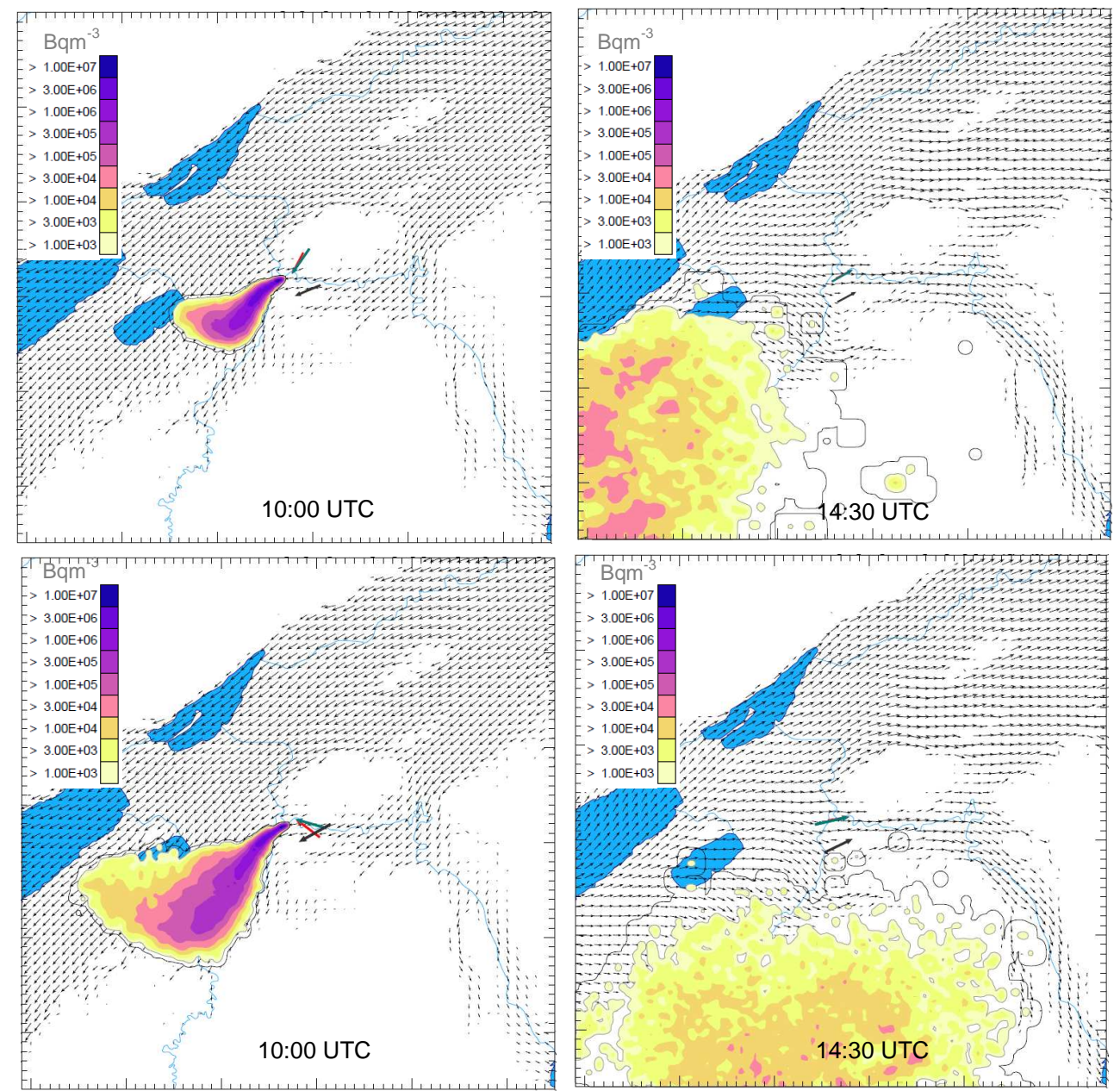

Fig. 9. Concentration levels of a virtual radioactive plume emitted at the Muehleberg nuclear power plant and wind fields based on COSMO-2 forecasts. The radioactive plume is calculated at surface level (1.5 ma.g.1.). Top row: dispersion predicted based on meteorological model forecasts, bottom row: dispersion simulated based on measured meteorology. Red arrow: winds at $10 \mathrm{~m}$ a.g.1., blue arrow: winds at $110 \mathrm{~m}$ a.g.l., black arrow: winds at $70 \mathrm{~m}$ on a nearby hill $450 \mathrm{~m}$ above the power plant site; plume release at 09:00 h UTC. The blue surfaces are lakes. Note that the arrows of the wind field and those of the wind observations are not to the same scale.

Acknowledgements. The authors thank the Swiss Federal Nuclear Safety Inspectorat (ENSI) for their financial and scientific support.

Edited by: A. Apituley

\section{References}

Bellinger, T. E.: Integrating a Doppler sodar with nuclear power plant meteorological data. Ninth Symposium on Integrated Observing and Assimilation Systems for the Atmosphere, Oceans, and Land Surface (IOAS-AOLS). The 85th AMS Annual Meeting (San Diego, CA), 10-13 January, 2005.

Benjamin, S. G., Schwartz, B. E., Koch, S. E., and Szoke, E. J.: The value of wind profiler data in U.S. weather forecasting. Bulletin of the American Meteorological Society, 85(12), 1871-1886, 2004.
Calpini, B.: Surface and upper air recent developments in MeteoSwiss. TECO 2008, 27-29 November, 2008, St. Petersburg, Russia, 2008.

Desiato, F.: A dispersion model evaluation study for real-time application in complex terrain, J. Appl. Meteorol., 30, 1207-1219, 1991.

Furumoto, J., Imura, S., Tsuda, T., Seko, H., Tsuyuki, T., and Saito, K.: The variational assimilation method for the retrieval of humidity profiles with the wind-profiling radar, J. Atmos. Oceanic Technol., 24(9), 1525-1545, 2007.

Hug, C., Kaufmann, P., and Ruffieux, D.: Validation of the high resolution numerical weather prediction model COSMO-2 with independent wind profiler measurement data. The $8^{\text {th }}$ International Symposium on Tropospheric Profiling: Integration of Needs, Technologies and Applications, 19-23 October 2009, Delft, The Netherlands, S07-O03, 2009.

Kaufmann, P. and Weber, R.: Classification of mesoscale wind fields in the MISTRAL field experiment, J. Appl. Meteorol., 35, 
1963-1979, 1996.

May, P. and Strauch, R.: Reducing the effect of ground clutter on wind profiler velocity measurements, J. Atmos. Oceanic Technol., 15, 579-586, 1998.

Pudykiewicz, J.: Numerical simulation of the transport of radioactive cloud from the Chernobyl nuclear accident, Tellus, 40B, 241-259, 1988.

Rossa, A., and Leuenberger, D.: Sensitivity of the LHN Scheme to Non-Rain Echoes, Meteorol. Appl., 15, 503-511, 2009.

Ruffieux, D., Huguenin, P., Calpini, B., Hug, C., and Maier, O.: Ground-based remote sensing profiling and Numerical Weather Prediction model to manage nuclear power plants meteorological surveillance in Switzerland. The $8^{\text {th }}$ International Symposium on Tropospheric Profiling: Integration of Needs, Technologies and Applications, 19-23 October 2009, Delft, The Netherlands, S08O05, 2009.

Schorling, M., Eickenbusch, H., and Swidersky, H.: On-line monitoring the Bavarian nuclear power plants applying a Lagrangian model, Int. J. Environ. Pollut., 14(1-6), 316-323, 2000.

Schraff, C.: Mesoscale data assimilation and prediction of low stratus in the Alpine region, Meteor. Atmos. Phys., 64, 21-50, 1997.
Smith Lorraine, T. and Benjamin, S. G.: Impact of network wind profiler data on a 3-h data assimilation system, B. Am. Meteorol. Soc., 74(5), 801-807, 1993.

Steppeler, J., Doms, G., Schaettler, U., Bitzer, H. W., Gassmann, A., Damrath, U., and Gregoric, G.: Meso-gamma scale forecasts using the nonhydrostatic model LM. Meteor. Atm. Phys., 82, 7596, 2003.

St-James, J. and Laroche, S.: Assimilation of wind profiler data in the Canadian meteorological centre's analysis systems, J. Atmos. Oceanic Technol., 22(8), 1181-1194, doi:10.1175/JTECH1765.1, 2005.

Weusthoff, T., Ament, F., Arpagaus, M., and Rotach, M.: Assessing the benefits of convection permitting models by neighborhood verification - examples from MAP D-PHASE, Mon. Weather Rev., early online release, doi:10.1175/2010MWR3380.1, 2010.

Yates, E., Gaffard, C., and Nash, J.: Wind profilers and their integration with other remote sensing systems to investigate the structure of the boundary layer. The 8th International Symposium on Tropospheric Profiling: Integration of Needs, Technologies and Applications, 19-23 October 2009, Delft, The Netherlands, S02P03-1, 2009. 